\title{
Long-term Performance of Repairs to Reinforced Concrete Exposed to Coastal Conditions
}

\author{
Sachie Sato ${ }^{1}$, Yoshihiro Masuda ${ }^{2}$ and Masaru Kakegawa ${ }^{3}$ \\ ${ }^{1}$ Department of Architecture, Tokyo City University, 1-28-1, Tamazutsumi1-28-1, Setagaya, \\ Tokyo,158-8557, Japan, s-sato@tcu.ac.jp \\ 2 Department of Architecture and Urban Design, Utsunomiya University, 7-1-2, Yoto, Utsunomiya, \\ Tochigi,321-8585, Japan, masuday@utsunomiya-u.ac.jp \\ ${ }^{3}$ Taiheiyo Materials Corporation, Tabata ASUKA Tower,6-1-1, Tabata, Kita-ku, Tokyo, 114-0014, \\ Japan, Masaru-Kakegawa@taiheiyo-m.co.jp
}

\begin{abstract}
Reinforced concrete (RC) specimens were treated using different combinations of surface coating and/or patch repair methods and materials, left in a coastal region with frost damage risk, and their properties characterized after 25 years of exposure. Specimens were prepared by chipping away concrete from one section of concrete block with embedded reinforcement bars to expose the bars, followed by patch repair and then surface coating. Four types of material were used for patch repair: cement mortar, styrene-butadiene rubber (SBR) polymer cement mortar, rust-resistant SBR polymer cement mortar, and lightweight epoxy mortar. Two types of material were used for surface coating: multi-layer textured and thin textured coating. Following exposure, cracks were visible only on the surfaces of untreated specimens, apparently due to rebar corrosion; they were absent from all specimens that had undergone surface coating and/or patch repair. In addition, the corrosion resistance of these methods and materials was investigated by measuring and comparing the surface areas of corroded rebar between three segments: the repaired part, the unrepaired part, and the boundary between them. Concrete carbonation and rebar corrosion were greatly dependent on surface coating material, with the multilayer-textured coating especially effective at blocking chloride penetration. In addition, rebar corrosion was more effectively prevented by patch repair with the SBR polymer cement mortar than with the lightweight epoxy mortar.
\end{abstract}

Keywords: Exposure Test, Corrosion, Cracking, Patch Repair Methods, Surface Coating.

\section{Introduction}

Various recent initiatives around the world have paralleled our transition to a sustainable society. In the construction industry, efforts have focused on reviewing and optimizing the resource usage of buildings: to this end, priority has been given to improving techniques to repair, renovate, and maintain existing concrete structures to extend their lifespan and ensure their long-term integrity.

Reinforced concrete (RC) buildings are designed with high durability in mind, with purported lifetimes of over 100 years. The fact is, however, that such structures can show signs of degradation such as cracking and peeling very soon after their completion, in as little as 10 20 years. To guarantee the durability and safe usage of RC buildings in the long term, their susceptibility to different deterioration factors present in their environment should be assessed, and used to inform suitable management strategies.

The present study models an RC structure located near the coast, at risk of salt damage from 
ambient chloride (Sato. K et.al. 2002) Specimens were initially treated using a selection of surface coating and/or patch repair methods and materials, left exposed, and then evaluated in terms of several physical characteristics to characterize the durability afforded by each combination. Exposure tests were performed in a coastal region of Hokkaido, the cold, northernmost prefecture of the long Japanese archipelago. Evaluation data from 25-year-old specimens were additionally compared with those of similar specimens exposed for 4.8 and 8 years.

\section{Experimental Overview}

Table 1 shows the types of materials used in the repairs. Table 2 details the content and properties of the concrete; Table 3 shows its mix composition. The concrete used had a 28-day compressive strength of $30.8 \mathrm{~N} / \mathrm{mm}^{2}$. Figure 1 is a structural schematic of the RC specimens. First, concrete was chipped away from a designated area of the RC slab, which had two reinforcing steel bars ("rebar") embedded in it. Next, this area was patched and its surface coated using a specific combination of materials. Concrete was removed to two different depths ("chipping depth"), defined relative to the embedded rebar: (A) chipping extended below the bar, allowing it to be completely covered with mortar, or (B) chipping reached the same depth as the rebar axis, meaning only half of it was covered with mortar. Figure 2 explains the notation of the specimen IDs in the Results section. Two-symbol IDs denote RC specimens, while threesymbol IDs denote the rebars embedded in them.
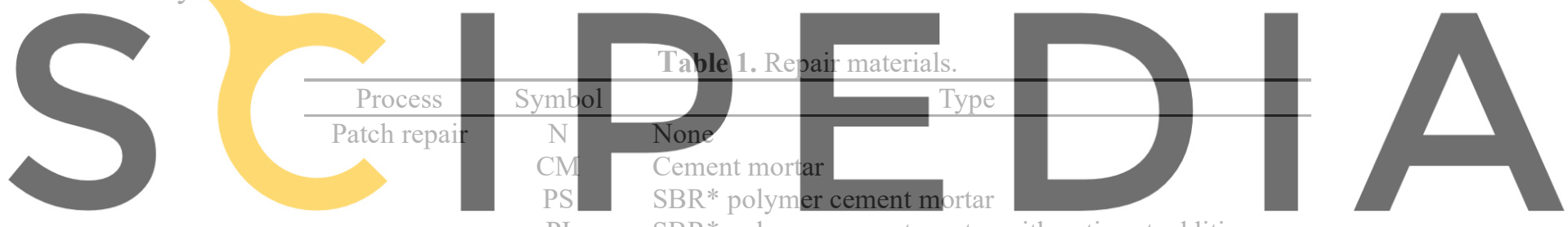

PI SBR* polymer cement mortar with anti-rust additive

Register for free at hțps/lwwWW. LE coating

Thin textured coat

Multi-layer textured coat

*SBR: styrene-butadiene rubber

Table 2. Concrete content and properties.

\begin{tabular}{cc}
\hline Materials & Properties \\
\hline Cement & Ordinary Portland cement \\
& Density: $3.16 \mathrm{~g} / \mathrm{cm}^{3}$ \\
\hline Fine aggregate & River sand \\
& Density $2.62 \mathrm{~g} / \mathrm{cm}^{3}$, F.M.2.64 \\
\hline Coarse aggregate & Crushed hard sandstone \\
& Density $2.64 \mathrm{~g} / \mathrm{cm}^{3}$, F.M.6.71 \\
\hline Air entraining agent & Natural resinate \\
\hline Rebar & Round steel bars with mill scale and acetone defatting: \\
& $\varphi 13 \mathrm{~mm}$, SR235 (SR24) (JIS G 3112) \\
\hline
\end{tabular}


Table 3. Concrete mix composition.

\begin{tabular}{|c|c|c|c|c|c|c|c|c|}
\hline $\begin{array}{l}\text { Target } \\
\text { slump } \\
(\mathrm{mm})\end{array}$ & $\begin{array}{c}\text { Target air } \\
\text { content } \\
(\%)\end{array}$ & $\begin{array}{l}\mathrm{W} / \mathrm{C} \\
(\%)\end{array}$ & $\begin{array}{l}\mathrm{S} / \mathrm{a} \\
(\%)\end{array}$ & Water & Cement & $\begin{array}{c}\text { Fine } \\
\text { aggregate }\end{array}$ & $\begin{array}{c}\text { Coarse } \\
\text { aggregate }\end{array}$ & $\begin{array}{c}\mathrm{AE} \\
(* \text { cement } \\
\text { weight }\end{array}$ \\
\hline & & & & & & $\mathrm{kg} / \mathrm{m}^{3}$ & & $(\%))$ \\
\hline 180 & 4.0 & 65.0 & 48.0 & 185 & 285 & 862 & 940 & 0.020 \\
\hline
\end{tabular}

These 'repaired' specimens were left at the exposure test site for predetermined lengths of time (43.025N, $140.53 \mathrm{E}, \sim 40 \mathrm{~m}$ from coastline: Figure 3$)$. At each timepoint, several specimens were broken apart and the rebar inside removed to measure the surface area affected by corrosion ("corrosion area") and the weight lost due to corrosion ("corrosion mass loss"). Carbonation depth and chloride penetration were measured in the broken concrete in parallel. Figure 4 shows the mean monthly temperatures of the region where the specimens were left exposed.

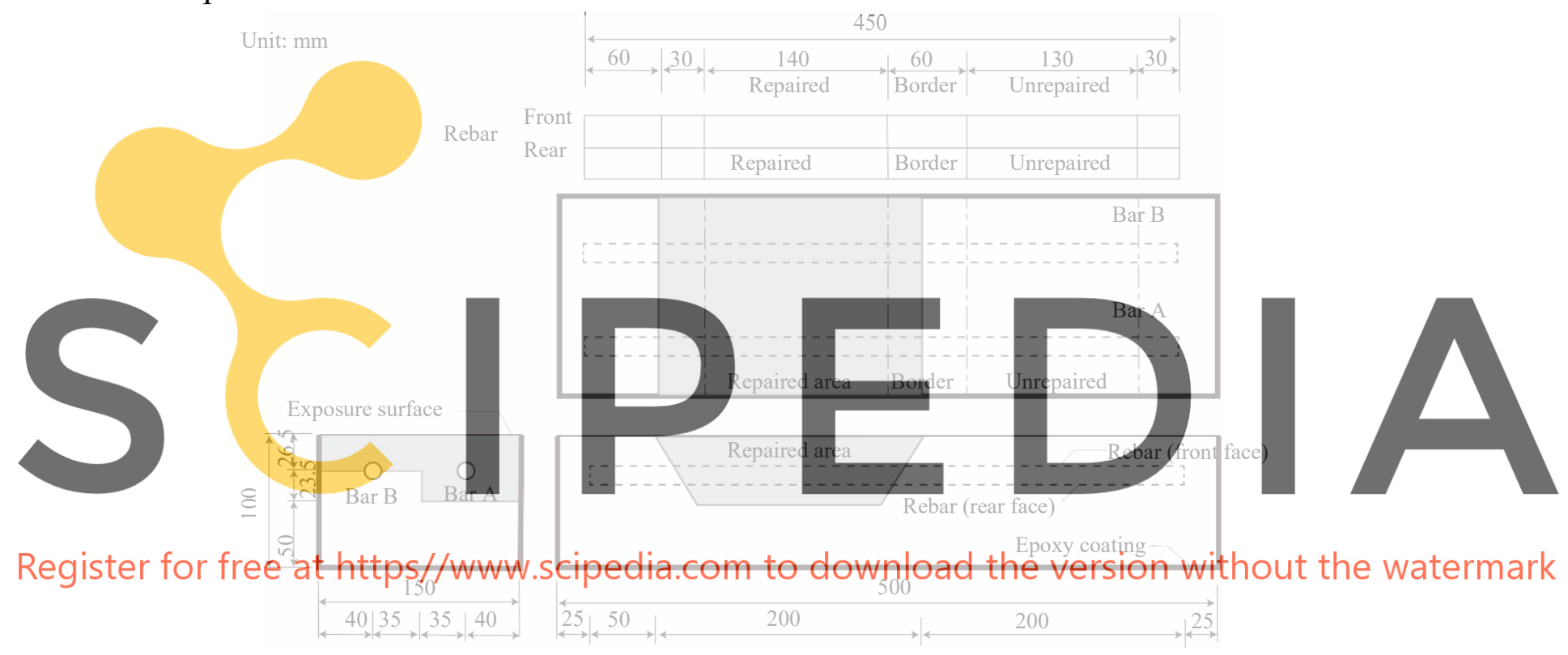

Figure 1. Schematic of RC specimen.

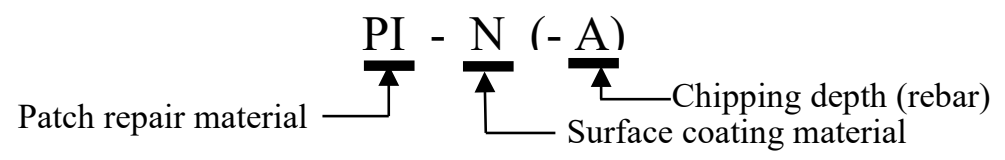

Figure 2. Specimen notation.

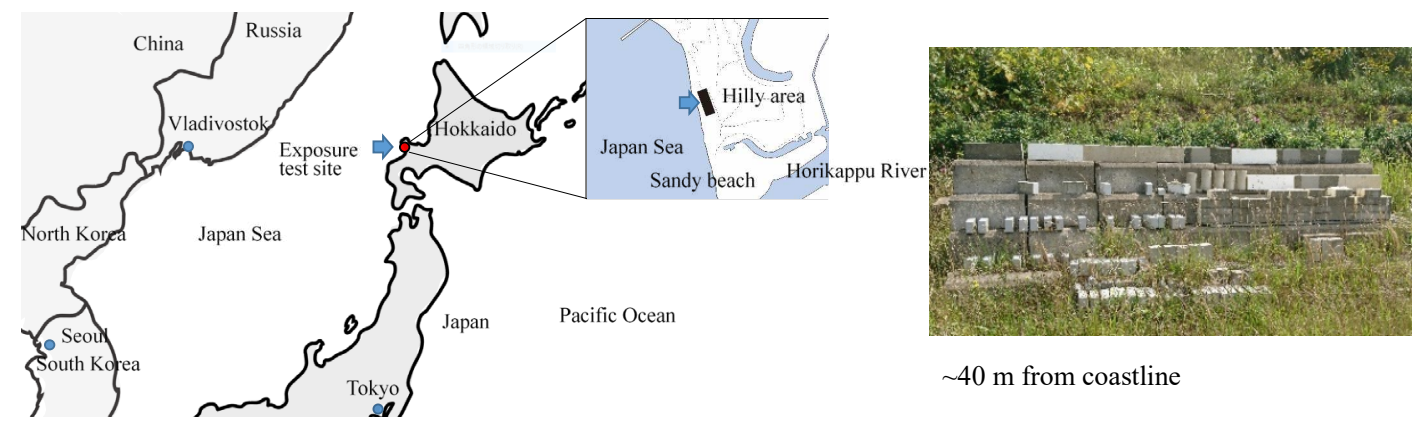

Figure 3. Exposure test site. 


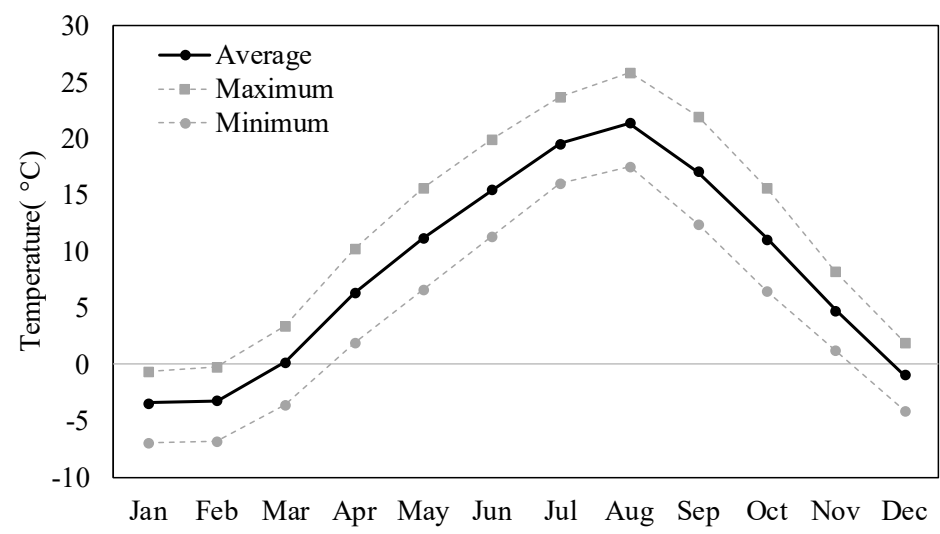

Figure 4. Mean air temperature by month at exposure test site.

\section{Results and Discussion}

\subsection{Carbonation Depth}

Figure 5 shows the measurement data for carbonation depth. Carbonation depth was most affected by the presence of surface coating itself, consistently measured deeper in specimens whose surfaces had not been coated at all (-N). When present, multilayer textured coating $(-\mathrm{S})$ provided superior protection to thin textured coating (-L): specimens treated with it experienced almost no carbonation at all, irrespective of patching mortar type, evidencing its excellent

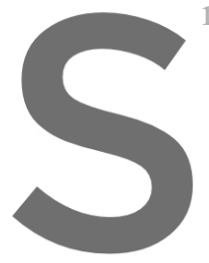
resistance to carbonatio
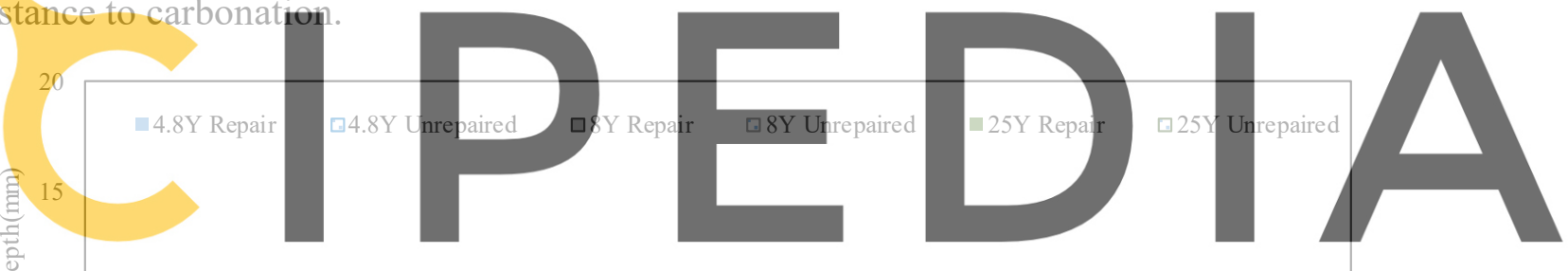

Register for ${ }_{\text {ree }}$ at https//www.scipedia.com to download the version without the watermark

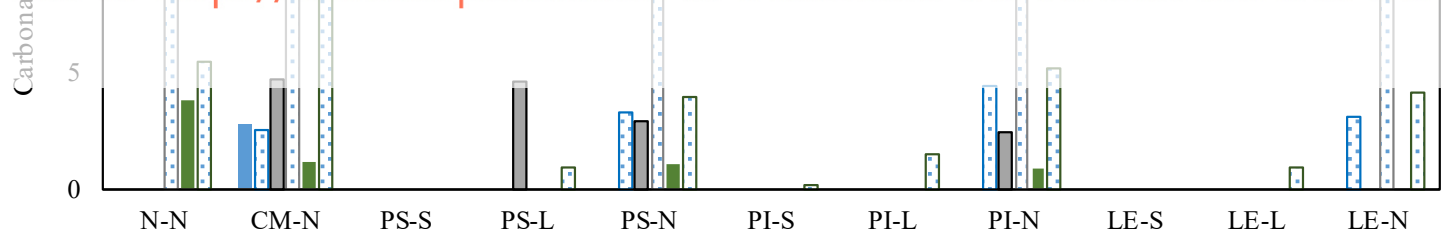

Figure 5. Carbonation depth.

\subsection{Rebar Corrosion}

Once removed from concrete, steel rebar was first visually graded, and then its degradation quantified by tracing and measuring the surface area of the regions affected by corrosion. Figure 6 contains photos of two bars affected by corrosion taken from a representative specimen (CM$\mathrm{N})$. Corrosion behavior clearly differs greatly between the repaired and unrepaired regions: interestingly, in the repaired part, it seems dependent on chipping depth (i.e. A versus B rebar). 


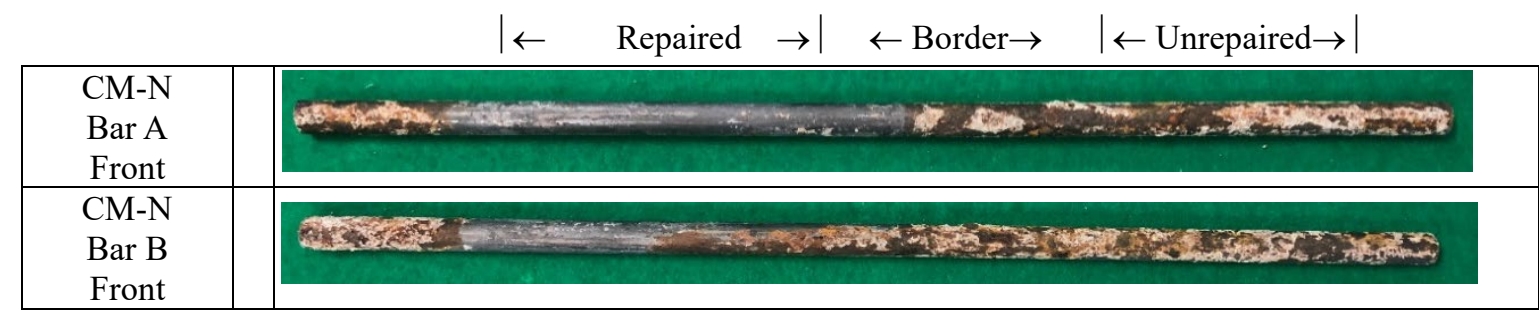

Figure 6. Rebar corrosion (CM-N, 25 years).

Next, rust was removed from the extricated bars by immersion in $10 \%$ di-ammonium citrate. Each bar was sectioned into three parts according to Figure 1 (Repaired, Border, and Unrepaired), and the corrosion mass loss calculated for each part (Nishimura N. et al.,2012, Kakegawa, M.et al.,2012). Corrosion speed was then calculated based on the mass loss using the following equation (Sato K. et al.,2002).

$$
\Delta W_{S}=\frac{\Delta W c \times W_{0}}{\varphi \times l \times \pi \times t}
$$

Where $\Delta \mathrm{Ws}$ is the rebar corrosion speed $\left(10-6 \mathrm{~g} / \mathrm{mm}^{2} / \mathrm{y}\right), \Delta \mathrm{Wc}$ is the mass loss due to rust $(\%), \mathrm{W} 0$ is the initial weight of the rebar $(\mathrm{g}), \varphi$ is its diameter $(13 \mathrm{~mm}), 1$ is its length in the part under analysis ( $\mathrm{mm}$ ), and $\mathrm{t}$ is the exposure length (year).

Figure 7 depicts correlations of rebar corrosion speed in the unrepaired versus border and repaired sections. Corrosion was effectively prevented by the repair techniques utilized, by and

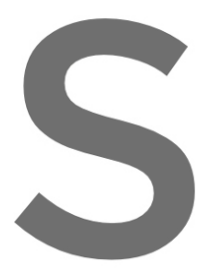
large proceeding at slower speeds in repaired than unrepaired rebar. Conssion speed was quite high in the border regio SBR polymer cement $(\mathrm{PI})$. This behavior differential in corrosion potential between the additive in the mortar. However, the same
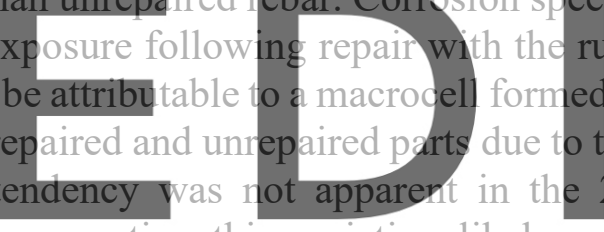

specimens repaired using the same material, suggesting this variation likely originated in

Register for free at https//WwW.Scipedia.com to download the version without the watermark
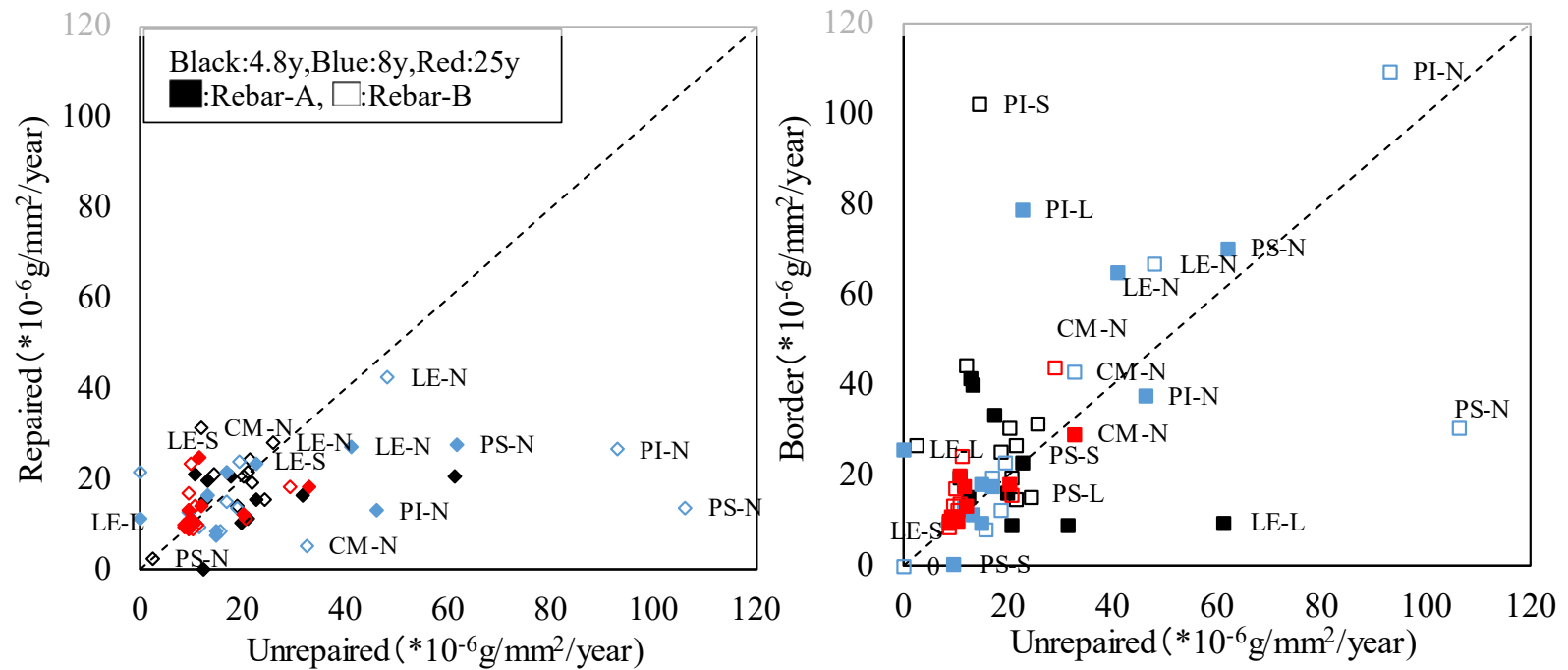

Figure 7. Rebar corrosion speed. 
Figure 8 separately depicts the associations between the rebar corrosion area (itself affected by chipping depth) and corrosion mass loss by type of patching material. Specimens not treated by patch repair or surface coating $(\mathrm{N}-\mathrm{N}-)$ experienced major mass loss, directly proportional to

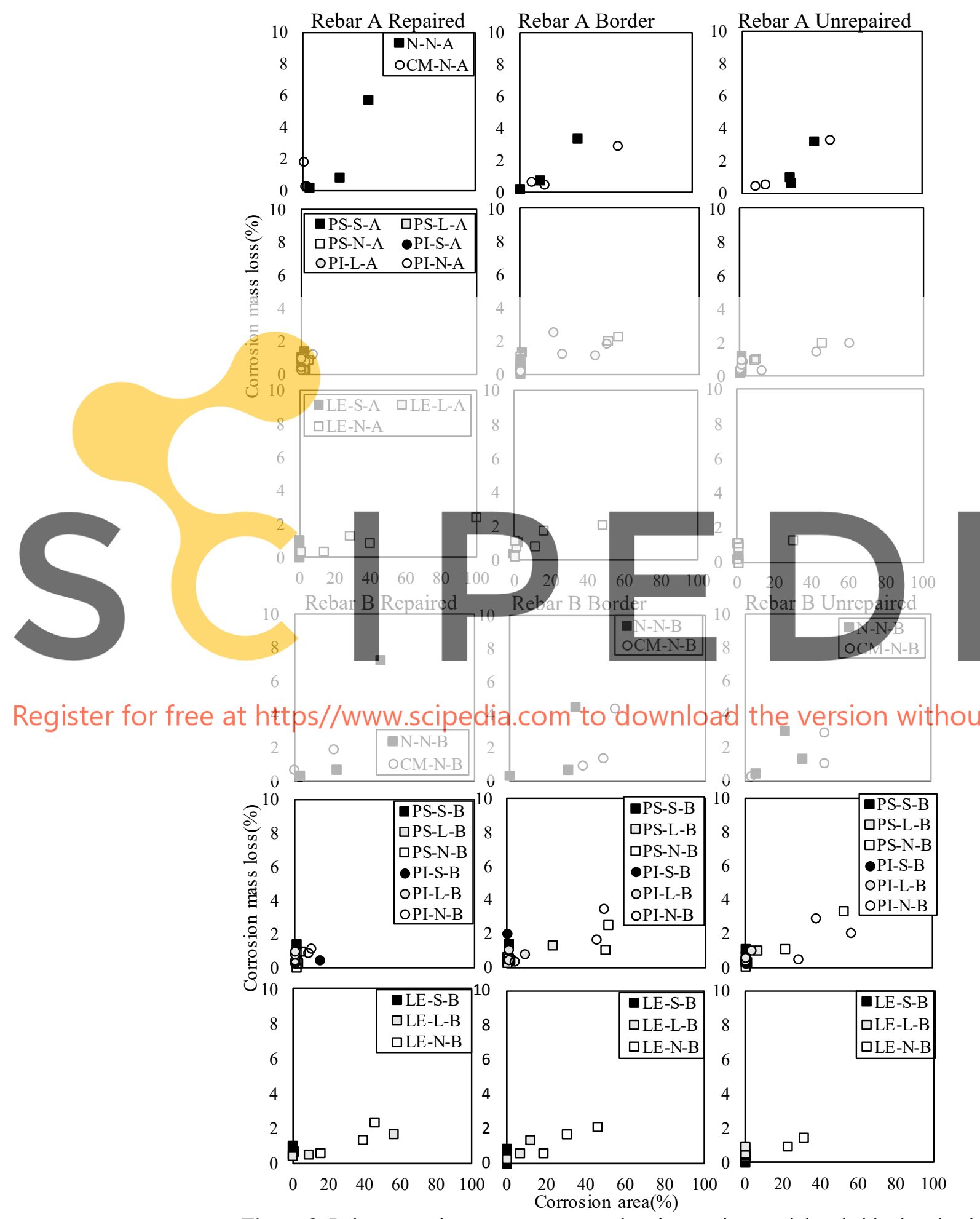

Figure 8. Rebar corrosion area versus mass loss by repair material and chipping depth. 
corrosion area. In addition, corrosion progressed not only along the surface of rebar, but also towards its interior. When cement mortar was used for patch repair (CM-), the corrosion area and mass loss of the repaired region tended to be greater for B rebar than for A rebar. This suggests that chipping away enough concrete so that the entire area surrounding the rebar can be coated with patching mortar should effectively protect against corrosion. In addition, the corrosion area and mass loss of the repaired region were lower when SBR-type polymer cements (PS, PI) were used as the patching mortar than for lightweight epoxy (LE), evidencing the former materials' superior ability to protect against corrosion in patch repairs. Corrosion was prevented rather poorly by LE: when it was used, corrosion tended to spread widely across the rebar surface in the repaired region. No matter which material was used for patch repairs, the usage of multi-layer textured coating (-S-) was associated with significant drops in both corrosion area and weight loss, suggesting this material effectively resists corrosion and block the penetration of chloride ions. The only difference between PI and PS is the presence of an anti-rust additive in the former. Figure 8 shows that both materials well protect against rebar corrosion in the repaired region, with only marginal benefits afforded by the anti-rust compound.

However, specimens repaired using PI or PS tended to experience greater rebar corrosion along the border and non-repaired parts, especially in the absence of finish: this suggests the occurrence of macro-cell corrosion due to differential susceptibility to chloride penetration between the repaired and unrepaired segments. Notably, the multi-layer textured finish was the thickest of all types tested, achieving high chloride resistance and little penetration in the border and unrepaired segments on the whole. This characteristic may be why serious rebar corrosion was never really observed in the border and unrepaired parts of specimens coated with it.

4 Conclusion
This study's findings illustrate how the corrosion resistanc

affected by the materials chosen for patch repair and surface coating, as well as by chipping depth, based on experimental data from exposure tests lasting $\sim 25$ years. They can be Register for free, at https/dWwW.scipedia.com to download the version without the watermark

Carbonation was most effectively prevented by the multi-layer textured coating material.

- Corrosion protection was greater when concrete chipping extended below the rebar than merely to the same depth.

- Rebar corrosion, as with carbonation, was most effectively prevented by the multi-layer textured coating material.

- Rebar was more resistant to corrosion following patch repair with SBR polymer cements than with lightweight epoxy. However, when surface coating was not performed, macrocell corrosion may have been triggered by a high differential in chloride environment between the boundary/unrepaired and repaired regions.

Going forward, the authors plan to analyze chloride penetration depth in order to further scrutinize its relationship with rebar corrosion.

\section{Acknowledgements}

This work was supported by JSPS KAKENHI Grant Numbers JP16K06591 and JP19K04695. 


\section{ORCID}

Sachie Sato: https://orcid.org/0000-0002-2299-2149

Yoshihiro Masuda: N/A

Masaru Kakegawa: N/A

\section{References}

Kakegawa.M., Masuda, Y., Matsubayashi, Y. and Kage, T.(2012). Long-term outdoor exposure test on the rate of corrosion test of reinforcing bar in concrete containing chloride ion, Journal of Structural and Construction Engineering (Transactions of AIJ), 77(672), 143-151, (In Japanese), doi:10.3130/aijs.77.143

Nishimura N.,Masuda, Y., Kage. T. and Matsubayashi, Y.(2010). Evalulation of effect on repaire of section repaire method of construction based on reinforcing bars mass decrease rate of the long-term exposure test body, Journal of Structural and Construction Engineering (Transactions of AIJ). .77(655), 1601-1608,(In Japanese) doi:10.3130/aijs.75.1601

Sato, K, Masuda, Y. et al., (2002). Outdoor exposure test on evaluation of repair reinforced concrete, Summaries of technical papers of annual meeting, Architectural Institute Japan, A-1, 625-626(In Japanese)
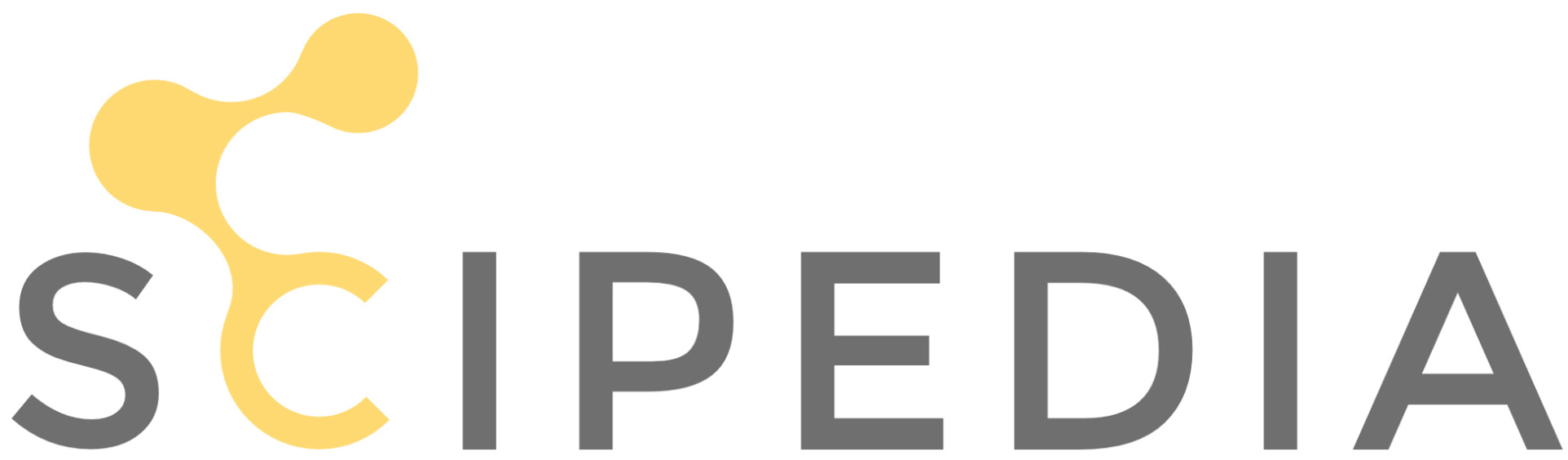

Register for free at https//www.scipedia.com to download the version without the watermark 